\title{
Clinical and Laboratory Features of Acute Porphyria: A Study of 36 Subjects in a Chinese Tertiary Referral Center
}

\author{
Jing Yang, ${ }^{1}$ Qianlong Chen, ${ }^{2}$ Hang Yang, ${ }^{2}$ Baolai Hua, ${ }^{3}$ Tienan Zhu, ${ }^{3}$ Yongqiang Zhao, \\ Huadong Zhu, ${ }^{1}$ Xuezhong Yu, ${ }^{1}$ Li Zhang, ${ }^{4}$ and Zhou Zhou ${ }^{2}$ \\ ${ }^{1}$ Emergency Department, Peking Union Medical College Hospital, Chinese Academy of Medical Sciences and \\ Peking Union Medical College, Beijing, China \\ ${ }^{2}$ State Key Laboratory of Cardiovascular Disease, Beijing Key Laboratory for Molecular Diagnostics of \\ Cardiovascular Diseases, Diagnostic Laboratory Service, Fuwai Hospital, National Center for Cardiovascular Diseases, \\ Chinese Academy of Medical Sciences and Peking Union Medical College, Beijing, China \\ ${ }^{3}$ Department of Hematology, Peking Union Medical College Hospital, Chinese Academy of Medical Sciences and \\ Peking Union Medical College, Beijing, China \\ ${ }^{4}$ Department of Clinical Laboratory, Peking Union Medical College Hospital, Chinese Academy of Medical Sciences and \\ Peking Union Medical College, Beijing, China \\ Correspondence should be addressed to Huadong Zhu; huadongzhu@hotmail.com and Zhou Zhou; fwcomd@126.com
}

Received 22 July 2016; Revised 29 September 2016; Accepted 5 October 2016

Academic Editor: Udayan Apte

Copyright (c) 2016 Jing Yang et al. This is an open access article distributed under the Creative Commons Attribution License, which permits unrestricted use, distribution, and reproduction in any medium, provided the original work is properly cited.

Porphyria is a group of eight metabolic disorders characterized by defects in heme biosynthesis. The presentation of porphyria is highly variable, and the symptoms are nonspecific, which accounts in part for delays in establishing a diagnosis. In this study, we report the characteristics of 36 Chinese acute porphyria patients. Most of them were female (33/36), and the median age was 25.3 years (range 18-45 years). The most frequent presenting symptom was abdominal pain (32/36). Hyponatremia was the most common electrolyte abnormality (29/36), and the serum sodium concentration was significantly negatively correlated with convulsion $(p=0.00)$. Genetic testing provided a precise diagnosis of the patients. Genetic analysis of the porphobilinogen deaminase $(P B G D)$ gene was performed for 10 subjects. Of them, 9 were found to harbor a mutation in the $P B G D$ gene, proving a diagnosis of acute intermittent porphyria, and, in 1 case, a novel Cys209Term mutation was found.

\section{Introduction}

Porphyria is a group of eight metabolic disorders, mainly inherited errors of metabolism characterized by defects in heme biosynthesis. Porphyria is classified into two major categories: (1) acute or inducible porphyria and (2) chronic cutaneous porphyria [1]. The presentation of porphyrias is highly variable, and the symptoms are nonspecific, which accounts in part for delays in establishing a diagnosis. There are four classes of acute hepatic porphyria: acute intermittent porphyria (AIP), hereditary coproporphyria (HCP), variegate porphyria (VP), and porphyria due to severe deficiency of delta-aminolevulinic acid (ALA) dehydratase porphyria (ALADP) [1].
Symptoms of porphyria, which occur in intermittent attacks and may be life-threatening, are caused by the excessive production of porphyrin precursors in the visceral, peripheral, autonomic, and central nervous systems [2]. Genetic testing could provide an early and accurate diagnosis and offer the opportunity to advise affected individuals to avoid drugs and other compounds that may provoke a lifethreatening crisis. It could also help to screen asymptomatic family members of patients with acute porphyria. The natural history and clinical and biochemical and genetic features of acute porphyrias have been described in Western countries $[3,4]$, but, to our knowledge, it has been described in the Chinese population only in case reports [5-12]. In this retrospective study, we analyzed the characteristics of 36 cases 
of acute porphyria from the Peking Union Medical College Hospital.

\section{Methods}

2.1. Study Design and Patients. The study design was approved by the Ethics Committee of the Institutional Review Board at the Peking Union Medical College Hospital (PUMCH).

From January 2013 to May 2016, a total of 36 patients were diagnosed with acute porphyria in the emergency center of the PUMCH. The following diagnostic criteria were used: (1) acute attack symptoms and (2) being positive for urine porphobilinogen (PBG). The clinical features and laboratory evaluation of these 36 patients were retrospectively reviewed.

Among the 36 patients, 10 agreed to have genetic testing for porphobilinogen deaminase $(P B G D)$ gene mutations. These 10 patients signed a written consent form stating their acceptance of the genetic testing.

2.2. Qualitative Screening Tests of Urinary PBG (WatsonSchwartz Method). Urine porphobilinogen (PBG) was quantitatively screened using the Watson-Schwartz method. Briefly, urine was added to Ehrlich's reagent $(0.7 \mathrm{~g}$ dimethylamine borane dissolved in $150 \mathrm{~mL}$ concentrated hydrochloric acid and $100 \mathrm{~mL}$ water). After 1-2 min, a saturated sodium acetate solution was added, and the nonspecific colors were removed by extraction with chloroform and n-butanol. A positive PBG result was indicated by a distinct pink color in the lower layer [13].

2.3. Genetic Testing. The molecular genetic testing of the $P B G D$ gene was performed by direct sequencing. All 14 exons of the $P B G D$ gene and a minimum of 20 base pairs of flanking intronic DNA for each exon were amplified by polymerase chain reaction (PCR) (Tiangen Biotech, Beijing, China) and subsequently sequenced using the BigDye Terminator Cycle Sequencing Kit version 3.1 (ABI Biosystems) on ABI PRISM 3730 Sequence Analyzer according to the manufacturer's instructions.

2.4. Statistics. All statistical analyses were performed using SPSS software (IBM SPSS for Windows, version 16.0, SPSS, Inc., Chicago, IL) for descriptive analysis. Chi-squared tests were employed for categorical variables while parametric Student's $t$-tests or Mann-Whitney $U$ tests were used for continuous counterparts, as appropriate. For all comparisons, a $p$-value $<0.05$ was considered to represent a significant difference. All statistical tests were 2-sided.

\section{Results}

In this cohort, the gender distribution was predominantly female ( 33 females, 3 males), and the median age was 25.3 years (range 18-45 years). As for the triggering factors, 28 out of the 36 patients $(77.8 \%)$ had cyclical attacks linked to the respective patient's menstrual cycle, 2 of the 36 patients $(5.6 \%)$ had a history of alcohol consumption, 3 of the 36 patients $(8.3 \%)$ had a history of severe dieting, and
TABLE 1: Clinical features and laboratory findings of acute porphyria.

\begin{tabular}{lc}
\hline Clinical manifestation $(n=36)$ & 32 \\
\hline Abdominal pain & 28 \\
Cyclical attacks & 26 \\
Constipation & 16 \\
Confusion & 12 \\
Convulsions & 10 \\
Tachycardia & 5 \\
Paresis & 3 \\
Numbness of extremities & 3 \\
Hypertension & 2 \\
Respiratory paralysis & 29 \\
\hline Laboratory findings & 14 \\
\hline Hyponatremia & $123.0 \pm 10.7$ \\
Severe hyponatremia $(<125 \mathrm{mEq} / \mathrm{L})$ & 22 \\
Serum Na (mEq/L) & $69.5 \pm 56.3$ \\
Transaminase elevation & 10 \\
ALT (U/L) & $117.6 \pm 17.9$ \\
Anemia & \\
Hemoglobin (g/L) & \\
\hline
\end{tabular}

TABLE 2: Diagnosis of acute porphyria.

\begin{tabular}{lc}
\hline Free erythrocyte protoporphyrin $(\mu \mathrm{g} / \mathrm{L})$ & $7.5 \pm 2.7$ \\
PBG positive & $36 / 36$ \\
Uroporphyrin positive & $22 / 36$ \\
Genetic testing & 10 \\
\hline
\end{tabular}

1 patient $(2.8 \%)$ had taken valproate prior to experiencing acute attacks.

3.1. Clinical Features and Laboratory Findings of Acute Porphyria. The clinical manifestations and laboratory findings of acute porphyria are summarized in descending order of frequency in Table 1. Other manifestations may include muscle weakness $(n=1)$, difficulty swallowing $(n=1)$, or sun sensitivity $(n=1)$. A total of $2 / 36$ patients progressed rapidly to acute respiratory insufficiency, and the correct diagnoses were missed for the other patients who were treated for seizures for more than 3 weeks in local hospitals.

Hyponatremia was the most common laboratory abnormality that occurred during the acute attacks (29/36 patients). Other abnormalities observed included transaminase elevation (21/36) and anemia (11/36). The serum sodium concentration was significantly negatively correlated with convulsions $(p=0.000, p$ value $<0.05)$. A total of 14 of 36 patients had severe hyponatremia $(<125 \mathrm{mEq} / \mathrm{L})$; all were suspected to have syndrome of inappropriate antidiuretic hormone secretion (SIADH).

Urinary PBG, uroporphyrin, and free erythrocyte protoporphyrin (FEP) were all screened in all patients with acute attacks, the results of which suggested a diagnosis of porphyria. The test results are listed in Table 2.

Genetic analysis for mutations in the $P B G D$ gene was performed in 10 patients from 8 families. Of them, 9 
TABLE 3: Summary of genetic analysis of mutations in the PBGD gene in 10 patients.

\begin{tabular}{|c|c|c|c|c|c|c|c|}
\hline Patient & & Clinical features & $\begin{array}{l}\text { Total length of } \\
\text { hospital stay } \\
\text { (days) }\end{array}$ & $\begin{array}{l}\text { Serum Na } \\
(\mathrm{mEq} / \mathrm{L})\end{array}$ & $\begin{array}{l}\text { Plasma osmotic } \\
\text { pressure }\end{array}$ & $\begin{array}{l}\text { Urine osmotic } \\
\text { pressure }\end{array}$ & $\begin{array}{l}\text { Mutation in } \\
P B G D \text { gene }\end{array}$ \\
\hline 1 & F21 & $\begin{array}{l}\text { Cyclical attacks, abdominal pain, } \\
\text { constipation, confusion, } \\
\text { convulsion, tachycardia }\end{array}$ & 13 & 107 & 245 & 447 & Ala330Pro [11] \\
\hline 2 & F31 & $\begin{array}{c}\text { Cyclical attacks, abdominal pain, } \\
\text { constipation }\end{array}$ & 5 & 130 & 280 & 270 & Ala330Pro [11] \\
\hline 3 & $\mathrm{~F} 24$ & Cyclical attacks, abdominal pain & 3 & 108 & 291 & 585 & NO \\
\hline 4 & M45 & $\begin{array}{c}\text { Cyclical attacks, abdominal pain, } \\
\text { urine retention }\end{array}$ & 10 & 109 & 312 & 355 & Arg173Trp [12] \\
\hline 5 & F26 & $\begin{array}{c}\text { Cyclical attacks, abdominal pain, } \\
\text { constipation }\end{array}$ & 9 & 118 & 280 & 732 & Arg173Trp \\
\hline 6 & F28 & $\begin{array}{l}\text { Cyclical attacks, abdominal pain, } \\
\text { confusion, convulsion }\end{array}$ & 7 & 112 & 281 & 476 & Arg173Trp \\
\hline 7 & $\mathrm{~F} 22$ & $\begin{array}{c}\text { Cyclical attacks, abdominal pain, } \\
\text { constipation, respiratory } \\
\text { paralysis }\end{array}$ & 11 & 130 & & & Trp283Term \\
\hline 8 & F23 & $\begin{array}{l}\text { Cyclical attacks, abdominal pain, } \\
\text { constipation, confusion, } \\
\text { convulsion, tachycardia }\end{array}$ & 10 & 113 & 244 & 730 & Trp283Term \\
\hline 9 & F34 & $\begin{array}{l}\text { Cyclical attacks, abdominal pain, } \\
\text { sun sensitivity, confusion, } \\
\text { convulsion, tachycardia }\end{array}$ & 7 & 112 & 241 & 325 & Arg173Trp \\
\hline 10 & F33 & $\begin{array}{l}\text { Cyclical attacks, abdominal pain, } \\
\text { constipation, hypertension and } \\
\text { renal dysfunction }\end{array}$ & 8 & 128 & 314 & 309 & Cys625Term \\
\hline
\end{tabular}

Patients 1 and 2 were cousins; patients 7 and 8 were sisters.

patients from 7 families were identified as carriers of known pathogenic mutations, including 2 nonsense and 5 missense mutations (Table 3). Four patients from 4 families had the same mutation (Arg173Trp). Two had been previously reported $[5,11]$. Of the mutations identified, Cys209Term is a novel PBGD mutation.

3.2. Treatment and Outcome. Once acute porphyria was diagnosed, therapeutic measures were taken for each of the patients, including a high-carbohydrate diet (250-300 g of glucose per day), fluid restriction $(<2000 \mathrm{~mL}$ per day), and prohibition of drugs that may be harmful to the patient. After acute porphyria was diagnosed, 34 of the 36 patients experienced relief of their symptoms of acute attack, and their lab findings returned to normal values after $6.94 \pm 2.16$ days (314 days, Table 3$)$. One patient, who experienced numbness of the extremities and respiratory paralysis, required 3 months to recover, while another patient (patient 7, Table 3 ) died as a result of the month-long delay of diagnosis in the local hospital, which resulted in progression to respiratory failure and death within a few days.

\section{Discussion}

Acute porphyria is a group of four gevetic disorders characterized by defective heme biosynthesis. There are four types of acute porphyria: (1) acute intermittent porphyria (AIP, OMIM 176000), which is an autosomal dominant disorder caused by partial deficiency of $P B G D$, the third enzyme in the heme biosynthetic pathway; (2) hereditary coproporphyria (HCP, OMIM 121300), which is caused by a deficiency of coproporphyrinogen oxidase (CPOX), the sixth enzyme in the heme biosynthetic pathway; (3) variegate porphyria (VP, OMIM 176200), which is caused by a deficiency of protoporphyrinogen oxidase (PPOX), the seventh enzyme in the heme biosynthetic pathway; and (4) ALA-dehydratasedeficient porphyria (ADP, OMIM 125270), which is caused by a deficiency of ALA dehydratase, the second enzyme in the porphobilinogen synthase pathway [2].

The clinical manifestations of acute porphyria are diverse and occur as intermittent attacks that may be life-threatening, and they are caused by the excessive production of porphyrin precursors in the visceral, peripheral, autonomic, and central nervous systems $[2,4,14-16]$.

In this study, gastrointestinal symptoms were the most frequently reported symptoms (abdominal pain and constipation), with most of the patients diagnosed as having an intestinal obstruction in their first and subsequent attacks. Neurological manifestations were also common (confusion, convulsions, paresis, numbness of the extremities, and respiratory paralysis), and most of the patients were misdiagnosed with epilepsy, but the convulsions may have been related to 
hyponatremia. Hyponatremia is the most common biochemical manifestation; 14 of 36 patients had severe hyponatremia $(<125 \mathrm{mEq} / \mathrm{L})$. Their urine osmolalities were all highly elevated ( $>100 \mathrm{mosmol} / \mathrm{kg}$ ), and they were all suspected to have syndrome of inappropriate antidiuretic hormone secretion $(\mathrm{SIADH})$. However, in the absence of serum ADH testing, we could not distinguish SIADH from reduced secretion of antidiuretic hormone [17]. To our knowledge, our report is the largest cohort of subjects with well-documented and wellcharacterized acute porphyria in China.

The prompt and accurate diagnosis of acute porphyria in China is limited by poor awareness among physicians. Measurements of urinary PBG, ALA, and porphyrins, plasma and fecal porphyrins, and erythrocyte PBG deaminase are important for the diagnosis and typing of porphyria, but, in China, almost none of the hospitals carry out these tests, so additional efforts are required to improve the clinical diagnosis and treatment of porphyria.

Genetic testing may improve the diagnosis and typing of porphyria and may also assist in identifying other carriers of mutations within the patient's family. Of the 36 patients with suspected AIP, 10 submitted to genetic analysis of the PBGD gene, and the diagnosis of AIP was subsequently confirmed in 9 of those patients. No mutation was found in the remaining patient (patient 3); however, analysis of the CPOX gene (causative gene for HCP) and the PPOX gene (causative gene for VP) was not performed. Patient 10, who had a novel mutation in the PBGD gene (Cys209Term), presented with common clinical manifestation of porphyria (cyclical attacks of constipation and abdominal pain) but also experienced continuous hypertension, renal dysfunction (creatine: 130$321 \mu \mathrm{mol} / \mathrm{L})$, and unexplained thrombocytopenia $(32-80 \times$ $10^{9}$ platelets/L), which were aggravated during both of her two pregnancies. Bonkovsky et al. [4] reported no significant associations among clinical or laboratory abnormalities and the general types of porphyria mutations. More data are needed to analyze the relationship between clinical presentation and patient genotype.

In China, hematin is not available to treat acute porphyria. Fortunately, with high carbohydrate intake and the avoidance of harmful drugs, our patients recovered almost fully from their acute attacks, although recovery required weeks or months.

\section{Conclusion}

Patients with acute porphyria attacks are usually women aged 18-45 years who present with severe, recurrent abdominal pain lasting for days. Constipation and hyponatremia are common during these acute attacks. The diagnosis of acute porphyria should be suspected, especially in women who present symptoms linked to their menstrual cycles more than once in the ED. Once suspected, the diagnosis of porphyria can be rapidly established by measuring urinary PBG. In China, genetic testing provides precise diagnosis and typing for the patient. Acute porphyria should be treated with intravenous glucose to avoid considerable morbidity and mortality. The prognosis is good if the disease is recognized early.

\section{Competing Interests}

The authors declare that there is no conflict of interests regarding the publication of this paper.

\section{References}

[1] R. Schmid, S. Schwartz, and C. J. Watson, "Porphyrin content of bone marrow and liver in the various forms of porphyria," A.M.A. Archives of Internal Medicine, vol. 93, no. 2, pp. 167-190, 1954.

[2] K. E. Anderson, J. R. Bloomer, H. L. Bonkovsky et al., "Recommendations for the diagnosis and treatment of the acute porphyrias," Annals of Internal Medicine, vol. 142, no. 6, pp. 439450, 2005.

[3] S. Besur, P. Schmeltzer, and H. L. Bonkovsky, "Acute porphyrias," Journal of Emergency Medicine, vol. 49, no. 3, pp. 305-312, 2015.

[4] H. L. Bonkovsky, V. C. Maddukuri, C. Yazici et al., "Acute porphyrias in the USA: features of 108 subjects from porphyrias consortium," American Journal of Medicine, vol. 127, no. 12, pp. 1233-1241, 2014.

[5] J. Yang, H. Wang, K. Yin et al., "A novel mutation in the porphobilinogen deaminase gene in an extended Chinese family with acute intermittent porphyria," Gene, vol. 565, no. 2, pp. 288-290, 2015.

[6] X.-F. Kong, Y. Han, X.-H. Li, D.-Y. Gao, X.-X. Zhang, and Q.-M. Gong, "Recurrent porphyria attacks in a Chinese patient with a heterozygous PBGD mutation," Gene, vol. 524, no. 2, pp. 401402, 2013.

[7] X.-P. Cao, L. Su, H.-P. Xiao, Y.-Y. Liu, Y.-B. Li, and L.-L. Xiu, "Three single nucleotide polymorphisms of porphobilinogen deaminase gene related to a Chinese patient with acute intermittent porphyria," National Medical Journal of China, vol. 88, no. 34, pp. 2414-2416, 2008.

[8] H.-Y. Li and Y.-H. Yang, "Misdiagnosis of acute intermittent porphyria in a case," Zhonghua Er Ke Za Zhi, vol. 41, no. 4, p. 271, 2003.

[9] P. Zhou, Z.-M. Ren, and Q. Gao, "One case of acute intermittent porphyria," Zhonghua Er Ke Za Zhi, vol. 42, no. 7, p. 531, 2004.

[10] C.-C. Yang, H.-C. Kuo, H.-L. You et al., "HMBS mutations in chinese patients with acute intermittent porphyria," Annals of Human Genetics, vol. 72, no. 5, pp. 683-686, 2008.

[11] T. Yuan, Y.-H. Li, X. Wang et al., "Acute intermittent porphyria: a diagnostic challenge for endocrinologist," Chinese Medical Journal, vol. 128, no. 14, pp. 1980-1981, 2015.

[12] Y. Li, H. Qu, H. Wang, H. Deng, and Z. Liu, "Novel A219P mutation of hydroxymethylbilane synthase identified in a Chinese woman with acute intermittent porphyria and syndrome of inappropriate antidiuretic hormone," Annals of Human Genetics, vol. 79, no. 4, pp. 310-312, 2015.

[13] J. E. Buttery, A. M. Carrera, and P. R. Pannall, "Analytical sensitivity and specificity of two screening methods for urinary porphobilinogen," Annals of Clinical Biochemistry, vol. 27, no. 2, pp. 165-166, 1990.

[14] J. A. Stein and D. P. Tschudy, "Acute intermittent porphyria: a clinical and biochemical study of 46 patients," Medicine (United States), vol. 49, no. 1, pp. 1-16, 1970.

[15] A. Goldberg, "Acute intermittent porphyria: a study of 50 cases," The Quarterly Journal of Medicine, vol. 28, no. 110, pp. 183-209, 1959. 
[16] P. Mustajoki and P. Koskelo, "Hereditary hepatic porphyrias in Finland," Acta Medica Scandinavica, vol. 200, no. 3, pp. 171-178, 1976.

[17] D. E. Lipschutz and J. M. Reiter, "Acute intermittent porphyria with inappropriately elevated $\mathrm{ADH}$ secretion," Journal of the American Medical Association, vol. 230, no. 5, pp. 716-717, 1974. 


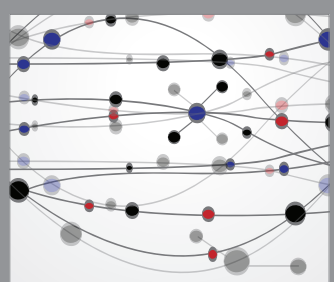

The Scientific World Journal
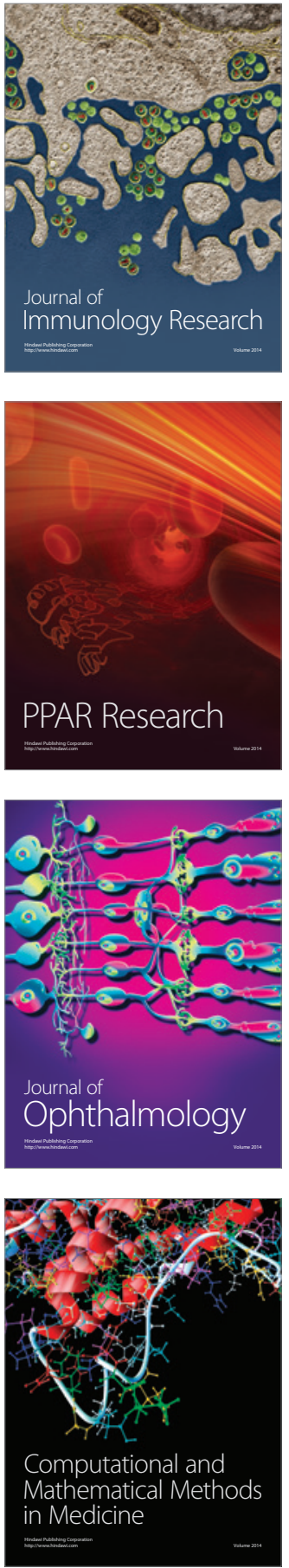

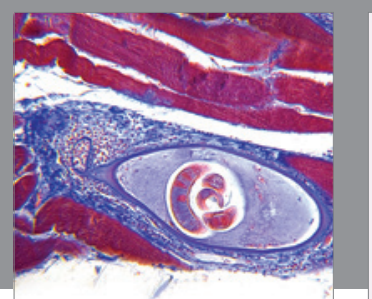

Gastroenterology Research and Practice

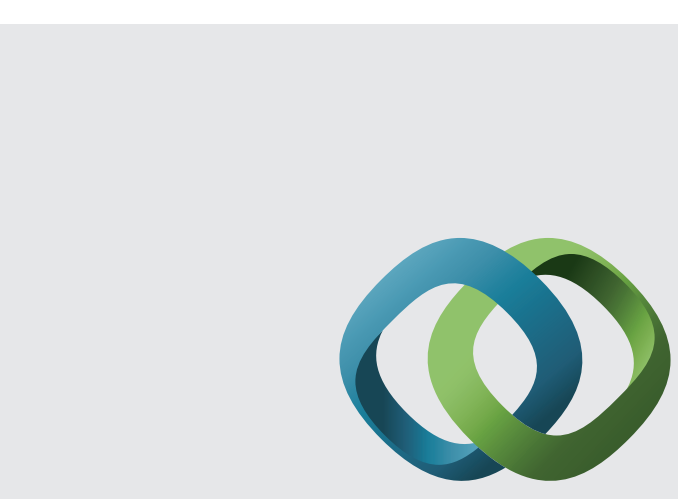

\section{Hindawi}

Submit your manuscripts at

http://www.hindawi.com
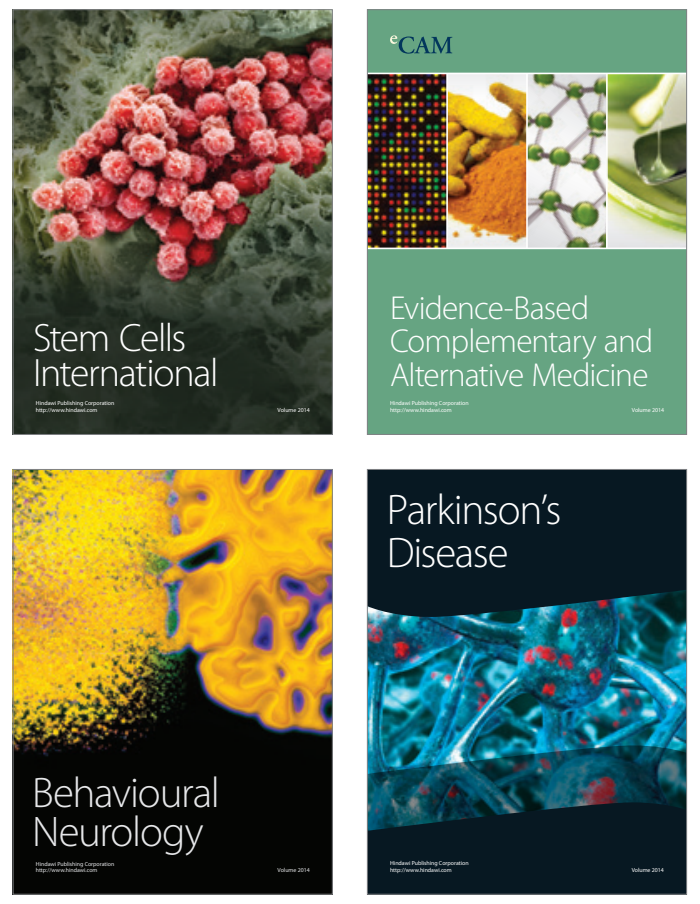
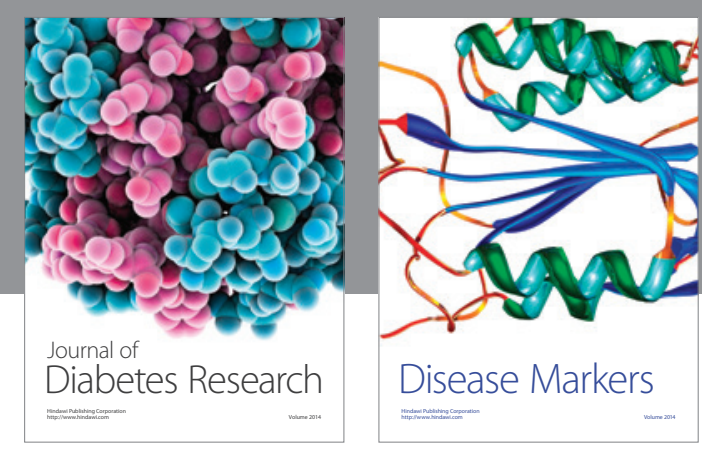

Disease Markers
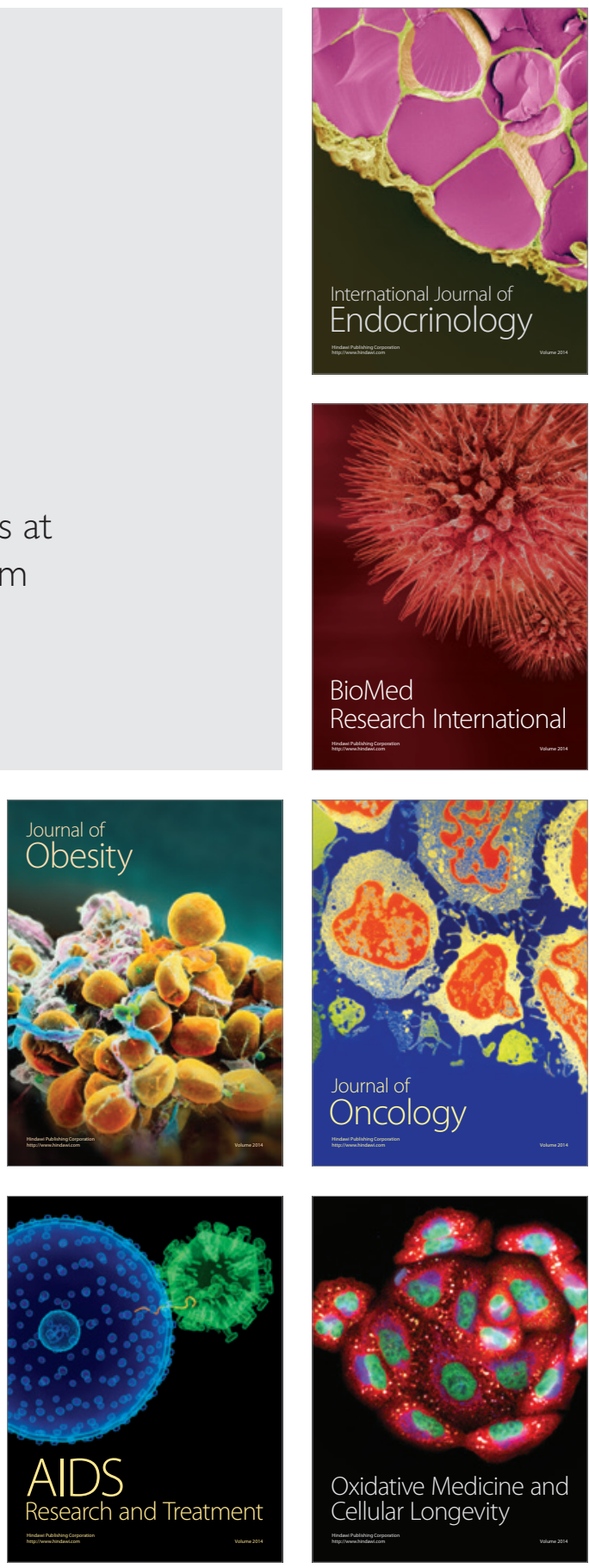